\title{
Surgical treatment of Chiari I malformation: indications and approaches
}

\author{
Tord D. Alden, M.D., Jeffrey G. OJemann, M.D., and T. S. Park, M.D. \\ Department of Neurosurgery, St. Louis Children's Hospital, Washington University School of \\ Medicine, St. Louis, Missouri
}

\begin{abstract}
Chiari I malformation is a well-described entity characterized by hindbrain herniation through the foramen magnum. Although the exact origin of congenital Chiari I malformation is unknown, it appears to be caused by a mismatch between the volume of the posterior fossa neural elements and the posterior fossa cranial content. Several theories have been proposed to describe the resultant pathophysiology of this mismatch. It is clear, however, that abnormal cerebrospinal fluid flow and velocity play a role in the symptoms and signs associated with this disorder. The authors will review the pathophysiology, clinical presentation, and treatment options for patients with Chiari I malformation.
\end{abstract}

\section{KEY WoRDS • Chiari malformation • syrinx • posterior fossa • decompression surgery $\bullet$ dural graft}

In 1891, Chiari presented his series conducted in autopsy examinations of patients with cerebellar ectopia in which he classified Type I as "elongation of the tonsils and medial parts of the inferior lobes of the cerebellum into cone-shaped projections, which accompany the medulla oblongata into the spinal canal." ${ }^{10,35}$ Chiari I malformation is often described as caudal displacement of the cerebellar tonsils below the level of the foramen magnum with or without syringomyelia. There are several theories that have been developed to explain both the cerebellar tonsillar descent and the frequently associated syringomyelia. ${ }^{1-3,5,7,8,17,26,28,37,41,42,44-47,51,53,55}$ Analysis of the data in the literature suggests several factors: 1) the ratio of the posterior fossa neural element volume to posterior fossa cranial volume is increased. This is related to either an underdeveloped occipital somite originating from the paraaxial mesoderm, which results in a smaller posterior fossa, or to an overgrowth of the supratentorial component and consequent shallow posterior fossa. . $^{1,8,41,42,46}$ 2) The CSF flow across the foramen magnum is abnormal during systole and diastole and, thus, increased tonsillar velocity and pulsation occur. ${ }^{2,5,47,53} 3$ ) The normal CSF flow in the spinal compartment is prevented.

Gardner ${ }^{20}$ proposed his hydrodynamic theory in which CSF pulsations are present in the developing brain. Failure of rhomboid roof perforation or medial and lateral foramina development results in a noncommunicating hydrocephalus. Increased pressure in the supratentorial compartment causes a shallow posterior fossa to develop due

\footnotetext{
Abbreviation used in this paper: $\mathrm{CSF}=$ cerebrospinal fluid.
}

to displacement of the tentorium. Hindbrain herniation ensues because the mismatch volume and pulsations of CSF force open the central spinal canal. ${ }^{20}$

Oldfield, et al. ${ }^{47}$ have suggested a different mechanism by which syringomyelia forms. Hindbrain herniation prevents the CSF flow to and from the spinal compartment that otherwise occurs during the cardiac cycle. Obstruction at the cervicomedullary junction results in increased CSF pressure in the spinal compartment during systole, and fluid is forced into the spinal cord through its surface. ${ }^{47}$

All of the aforementioned theories are supported, in part, through the success of surgical intervention performed to correct these pathological abnormalities. That new theories continue to be proposed nearly 30 years after Gardner's publication confirms that the origin of Chiari I malformation remains controversial and incompletely understood.

The pathophysiology of acquired Chiari I malformations, in most cases, is better characterized. These malformations are thought to be caused by a pressure gradient across the cranial and spinal CSF compartments, most commonly due to CSF diversion in the spinal component or increased cranial pressure, as seen in cases of supratentorial mass lesions or hydrocephalus..$^{11,29,34,49}$

\section{PRESENTATION AND EVALUATION OF PATIENTS WITH CHIARI I MALFORMATION}

There have been case reports of patients with unusual presentations, including hypoglycemia, ${ }^{50}$ developmental delay, ${ }^{6}$ paroxysmal rage, ${ }^{30}$ precocious puberty, ${ }^{31}$ glosso- 
pharyngeal neuralgia, ${ }^{56}$ cardiopulmonary arrest, ${ }^{39}$ and transient quadriparesis after minor trauma. ${ }^{9,38}$ Patients most commonly present with headache or neck pain, often exacerbated by physical exertion or neck movement. ${ }^{17}$ The majority of patients present with symptoms and signs that can divided into two subsets: 1) posterior fossa compression/foramen magnum obstruction or 2) spinal cord dysfunction (Table 1). In $25 \%$ of patients with Chiari I malformation, brainstem compression or syringobulbia results in brainstem dysfunction, commonly as downbeating nystagmus, sleep apnea, respiratory dysfunction, aspiration, vocal cord dismotility, extraoccular eye movement abnormality, hearing loss, dysphagia, and dysarthria. Cerebellar compression manifests as nystagmus, ataxia, dizziness, and dyarthria. Spinal cord dysfunction is caused by canal compression or syringomyelia. Generally, in approximately $50 \%$ of patients with Chiari I malformation and in up to $90 \%$ of those with spinal cord symptoms an associated syrinx will be present. ${ }^{17}$

Initial workup includes examination of supratentorial structures to ensure the absence of a mass lesion or hydrocephalus. In a patient in whom a shunt of any kind is in place, it is important to determine that the device is functioning adequately. To assess causation and to allow presurgical planning, it is important to evaluate spinal stability, especially in the setting of neck pain or spinal dysfunction. Grabb, et al., ${ }^{23}$ have advocated the assessment of the degree of ventral brainstem compression. In patients with significant ventral brainstem compression an anterior decompressive procedure may be warranted prior to treating the malformation.

The use of cine cardiac-gated magnetic resonance imaging to assess CSF flow can be helpful, especially in a patient in whom a decompressive procedure has been previously performed. . $^{2,4,5,7,12,16,28,37,42,46,47,51,53-55}$

\section{OUR EXPERIENCE}

Between 1998 and 2001, we examined 21 patients surgically treated for Chiari I malformation. The average age was 9 years (range 1-20 years), and the mean follow-up period was 16 months (range 1-48 months); 20 cases were congenital and one was acquired after the placement of a lumboperitoneal shunt. Twelve $(57 \%)$ were female and nine $(43 \%)$ were male. Eleven patients $(52 \%)$ presented with headache, four (19\%) with neck pain, five (24\%) with cranial nerve dysfunction, four (19\%) with cerebellar signs, $11(52 \%)$ with spinal cord dysfunction, three (14\%) with scoliosis, and three (14\%) presented with developmental delay. Ten patients presented with a syrinx. We

TABLE 1

Subset of signs and symptoms in patients with Chiari I malformation

\begin{tabular}{cc}
\hline \hline Factor & Signs \& Symptoms \\
\hline posterior fossa compression & $\begin{array}{c}\text { headache, neck pain, cranial nerve dys- } \\
\text { function, cerebellar signs, respiratory } \\
\text { spinal cord dysfunction } \\
\text { dysethesia, dissociated sensation, sen- } \\
\text { sory level, scoliosis, spasticity, loss } \\
\text { of fine motor function, bladder \& } \\
\text { bowel dysfunction }\end{array}$ \\
\hline
\end{tabular}

used the following surgical approach (Fig.1): a limited suboccipital craniectomy and C-1 laminectomy with 1) scoring of dura but leaving it intact (three patients [14\%]); 2) durotomy with duraplasty (four patients [19\%]); or 3) intradural exploration, resection of cerebellar tonsils, and duraplasty (12 patients [57\%]). One patient, initially treated elsewhere, underwent a repeated posterior fossa decompression and cranioplasty for cerebellar subsidence into the previously made decompression site. In one patient with acquired Chiari I malformation, the lumboperitoneal shunt was replaced with a ventriculoperitoneal shunt system. As of last follow-up examination symptoms had resolved in 14 patients $(67 \%)$, improved in six (29\%), and remained the same in one patient. Scoliosis was stable in two and progressive in one; no patient required spinal fusion. Of the 10 patients with syringomyelia, the syrinx resolved in eight, decreased in one, and remained the same size in one. There were two patients with complications: one with pseudomeningocele and meningitis and one with CSF leakage.

\section{SURGICAL APPROACH}

Many different approaches, which have evolved over time, have been described in the literature. In the past, plugging of the obex, placement of a stent in the fourth ventricle, extensive posterior fossa craniectomy, and multiple cervical laminectomies have been suggested as viable treatment options of Chiari I malformations. In an effort to define the current surgical strategies, the members of the Pediatric Section of the American Association of Neurological Surgeons were surveyed as to the surgical approach they used in pediatric patients with Chiari I malformation. ${ }^{25}$ Only $9 \%$ recommended performing decompressive surgery in asymptomatic patients. For the treatment of symptomatic patients, various approaches were used: approximately $20 \%$ recommended only osseous decompression; $30 \%$ recommended osseous decompression with dural grafting; $25 \%$ performed osseous decompression with dural grafting and intradural dissection of adhesions; and $30 \%$ recommended osseous decompression with dural grafting, intradural dissection, and tonsillar manipulation and resection. Those surveyed tended to perform a more aggressive decompression and intradural dissection when a syrinx was present. Although these data indicate the current practice regimen among neurosurgeons, there have been no prospective studies in which one treatment form is directly compared with another.

Simple decompression is advocated based on histological analysis of the dural band. ${ }^{45}$ Compared with healthy controls, the authors found an increase in collagen fibers, hyalinous nodules, and calcification in the dural band of patients with Chiari I malformation. The success of the decompressive procedure should be confirmed using intraoperative ultrasonography and further decompression should be performed if the ultrasonographic findings prove it to be inadequate. ${ }^{15,43,57}$ Further decompression can be achieved by scoring the dura's outer leaf and thus promoting expansion. The extent of osseous decompression is important. If too much bone is removed, patients are placed at risk for cerebellar subsidence and recurrence of symptoms. Tokuno, et al., ${ }^{52}$ attempted to address the small posterior fossa by conducting an expansive suboccipital 


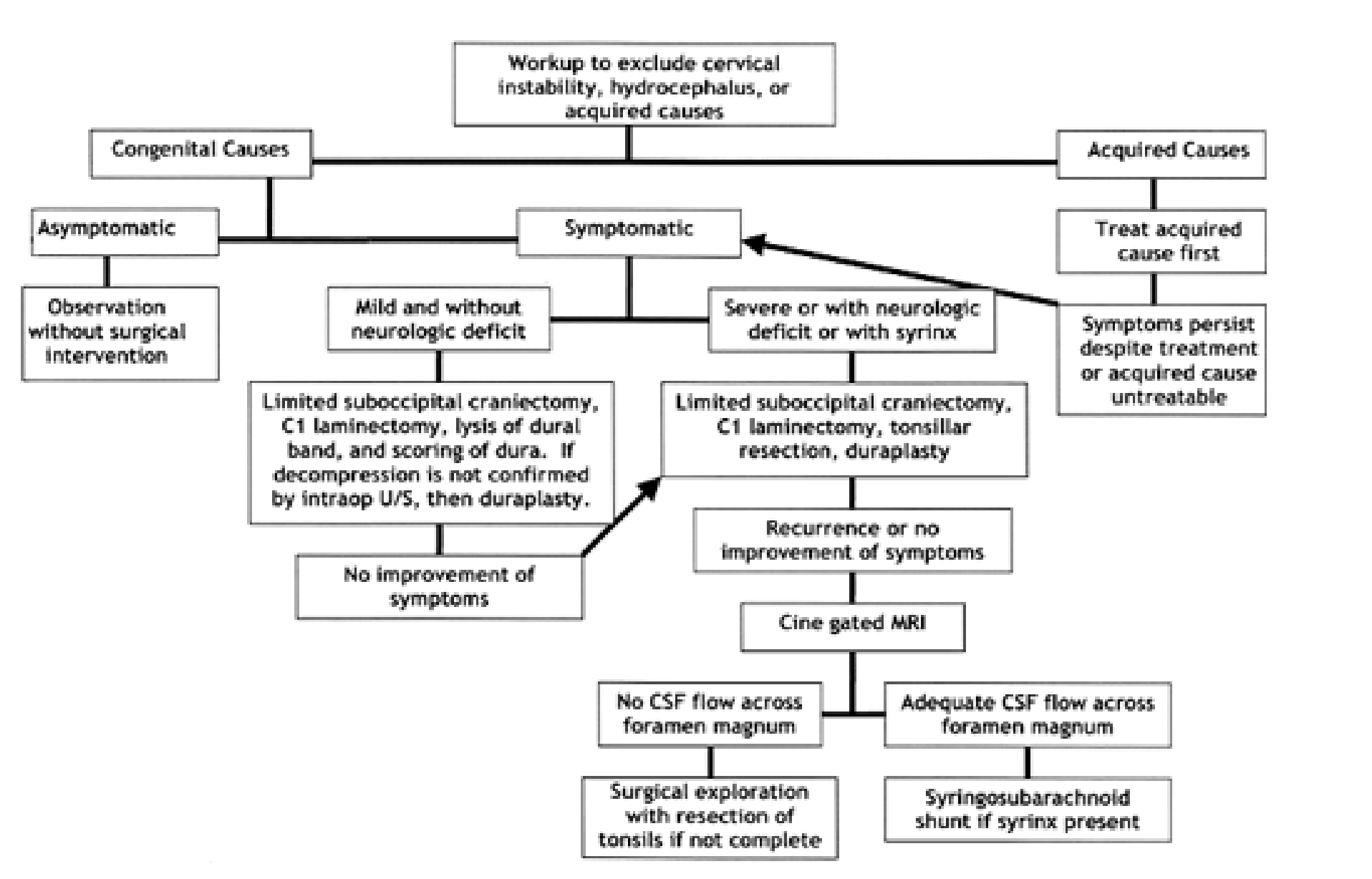

Fig. 1. Algorithm used to treat Chiari I malformation.

cranioplasty. We recommend performing a limited suboccipital craniectomy to enlarge the foramen magnum and allow for both decompression and maintenance of the posterior fossa neural elements.

Krieger, et al., ${ }^{36}$ recommend durotomy without duraplasty and have reported surgery-related outcome and complications comparable with those achieved by authors who advocate duraplasty, plugging of the obex, and tonsillar resection. Other authors have emphasized that duraplasty is essential for the prevention of scar formation and recurrent symptoms. ${ }^{13,14,16,18,21,41,43,48}$ Debate still exists as to whether, once the dura is opened, arachnoid dissection should be performed. One benefit of arachnoid dissection, in the setting of Chiari I malformation, is that it allows the surgeon to release adhesions that could potentially contribute to obstruction of CSF flow from the fourth ventricle to the spinal canal.

Resection of the cerebellar tonsils has been advocated as a way to improve the volume mismatch and to increase communication between the fourth ventricle and the spinal compartment. ${ }^{19,24,48}$ No neurological deficit has been demonstrated as a result of tonsillar resection; however, the exact function of this structure is largely unknown.

There has been a recent resurgence in the initial use of a syringosubarachnoid shunt in the treatment of patients with Chiari I malformation and syringomyelia. 22,27,32,33 Although these reports suggest that this therapy leads to an increased rate of recovery and improved resolution of the syrinx, it must be noted that the underlying pathophysiology is not addressed. In the setting of symptoms not related to spinal dysfunction, this approach is not recommended.

\section{OUTCOME AND COMPLICATIONS}

The results of treatment are difficult to assess given the absence of uniform outcome measures as well as a randomized controlled trial in which the different treatments are compared. In most papers in which outcome is discussed the authors have reported an 80 to $90 \%$ rate of good outcome, with either resolution of the symptoms or cessation of progression. Presenting symptoms associated with a good outcome include headache, cervical pain, mild scoliosis, and sleep apnea; ${ }^{44}$ those associated with poor outcome include increased length of symptoms, muscle atrophy, ataxia, and nystagmus. ${ }^{16,40}$ The most common complications include postoperative hemorrhage, CSF leakage, aseptic or bacterial meningitis, and recurrence. Other reported complications include cervical instability and cerebellar subsidence.

\section{CONCLUSIONS}

In light of the many theories of pathophysiology, broad clinical presentations, and multitude of surgical interventions with variable outcomes, it is no wonder that a single 
surgical approach does not exist. We recommend tailoring the surgical approach to treat the dominant clinical problem. Proper patient selection is critical to prevent unnecessary procedures and maximize outcome.

\section{References}

1. Amin-Hanjani S, Sathi S, Scott RM: De novo Chiari-I malformation in infants demonstrated by sequential magnetic resonance imaging scans. Report of two cases. Pediatr Neurosurg 22:299-302, 1995

2. Armonda RA, Citrin CM, Foley KT, et al: Quantitative cinemode magnetic resonance imaging of Chiari I malformations: an analysis of cerebrospinal fluid dynamics. Neurosurgery 35: 214-224, 1994

3. Atkinson JL, Kokmen E, Miller GM: Evidence of posterior fossa hypoplasia in the familial variant of adult Chiari I malformation: case report. Neurosurgery 42:401-404, 1998

4. Batzdorf U: Chiari I malformation with syringomyelia. Evaluation of surgical therapy by magnetic resonance imaging. J Neurosurg 68:726-730, 1988

5. Bhadelia RA, Bogdan AR, Wolpert SM, et al: Cerebrospinal fluid flow waveforms: analysis in patients with Chiari I malformation by means of gated phase-contrast MR imaging velocity measurements. Radiology 196:195-202, 1995

6. Brill CB, Gutierrez J, Mishkin MM: Chiari I malformation: association with seizures and developmental disabilities. J Child Neurol 12:101-106, 1997

7. Brugieres P, Idy-Peretti I, Iffenecker C, et al: CSF flow measurement in syringomyelia. AJNR 21:1785-1792, 2000

8. Caldemeyer KS, Boaz JC, Wappner RS, et al: Chiari I malformation: association with hypophosphatemic rickets and MR imaging appearance. Radiology 195:733-738, 1995

9. Callaway GH, O'Brien SJ, Tehrany AM: Chiari I malformation and spinal cord injury: cause for concern in contact athletes? Med Sci Sports Exerc 28:1218-1220, 1996

10. Chiari H: Ueber Veränderungen des Kleinhirns infolge von Hydrocephalie des Grosshirns. Dtsch Med Wschr 17:1172-1175, 1891

11. Chumas PD, Armstrong DC, Drake JM, et al: Tonsillar herniation: the rule rather than the exception after lumboperitoneal shunting in the pediatric population. J Neurosurg 78:568-573, 1993

12. Curless RG, Quencer RM, Katz DA, et al: Magnetic resonance demonstration of intracranial CSF flow in children. Neurology 42:377-381, 1992

13. Dauser RC, DiPietro MA, Venes JL: Symptomatic Chiari I malformation in childhood: a report of 7 cases. Pediatr Neurosci 14:184-190, 1988

14. Di Lorenzo N, Palma L, Palatinsky E, et al: "Conservative" cranio-cervical decompression in the treatment of syringomyeliaChiari I complex. A prospective study of 20 adult cases. Spine 20:2479-2483, 1995

15. Dure LS, Percy AK, Cheek WR, et al: Chiari type I malformation in children. J Pediatr 115:573-576, 1989

16. Dyste GN, Menezes AH, VanGilder JC: Symptomatic Chiari malformations. An analysis of presentation, management, and long-term outcome. J Neurosurg 71:159-168, 1989

17. Elster AD, Chen MY: Chiari I malformations: clinical and radiologic reappraisal. Radiology 183:347-353, 1992

18. Feldstein NA, Choudhri TF: Management of Chiari I malformations with holocord syringohydromyelia. Pediatr Neurosurg 31:143-149, 1999

19. Fischer EG: Posterior fossa decompression for Chiari I deformity, including resection of the cerebellar tonsils. Childs Nerv Syst 11:625-629, 1995

20. Gardner WJ: Hydrodynamic mechanism of syringomyelia: its

\section{T. D. Alden, J. G. Ojemann, and T. S. Park}

relationship to myelocele. J Neurol Neurosurg Psychiatry 28: 247-259, 1965

21. Ghanem IB, Londono C, Delalande O, et al: Chiari I malformation associated with syringomyelia and scoliosis. Spine 22: 1313-1318, 1997

22. Goel A, Desai K: Surgery for syringomyelia: an analysis based on 163 surgical cases. Acta Neurochir 142:293-302, 2000

23. Grabb PA, Mapstone TB, Oakes WJ: Ventral brain stem compression in pediatric and young adult patients with Chiari I malformations. Neurosurgery 44:520-528, 1999

24. Guyotat J, Bret P, Jouanneau E, et al: Syringomyelia associated with type I Chiari malformation. A 21-year retrospective study on 75 cases treated by foramen magnum decompression with a special emphasis on the value of tonsils resection. Acta Neurochir 140:745-754, 1998

25. Haroun RI, Guarnieri M, Meadow JJ, et al: Current opinions for the treatment of syringomyelia and Chiari malformations: survey of the Pediatric Section of the American Association of Neurological Surgeons. Pediatr Neurosurg 33:311-317, 2000

26. Hida $\mathrm{K}$, Iwasaki $\mathrm{Y}$, Imamura $\mathrm{H}$, et al: Birth injury as a causative factor of syringomyelia with Chiari type I deformity. J Neurol Neurosurg Psychiatry 57:373-374, 1994

27. Hida K, Iwasaki Y, Koyanagi I, et al: Surgical indication and results of foramen magnum decompression versus syringosubarachnoid shunting for syringomyelia associated with Chiari I malformation. Neurosurgery 37:673-679, 1995

28. Hofmann E, Warmuth-Metz M, Bendszus M, et al: Phase-contrast MR imaging of the cervical CSF and spinal cord: volumetric motion analysis in patients with Chiari I malformation. AJNR 21:151-158, 2000

29. Huang PP, Constantini S: "Acquired" Chiari I malformation. Case report. J Neurosurg 80:1099-1102, 1994

30. Hudgins RJ: Paroxysmal rage as a presenting symptom of the Chiari I malformation. Report of two cases. J Neurosurg 91: 328-329, 1999

31. Interlici S, Montanari E, Conrieri M, et al: A patient with early puberty associated with Chiari 1 malformation. J Pediatr Endocrinol Metab 13:849-851, 2000

32. Isu T, Iwasaki Y, Akino M, et al: Hydrosyringomyelia associated with a Chiari I malformation in children and adolescents. Neurosurgery 26:591-597, 1990

33. Iwasaki Y, Hida K, Koyanagi I, et al: Reevaluation of syringosubarachnoid shunt for syringomyelia with Chiari malformation. Neurosurgery 46:407-413, 2000

34. Johnston I, Jacobson E, Besser M: The acquired Chiari malformation and syringomyelia following spinal CSF drainage: a study of incidence and management. Acta Neurochirurgica 140:417-428, 1998

35. Koehler PJ: Chiari's description of cerebellar ectopy (1891). With a summary of Cleland's and Arnold's contributions and some early observations on neural-tube defects. J Neurosurg 75:823-826, 1991

36. Krieger MD, McComb JG, Levy ML: Toward a simpler surgical management of Chiari I malformation in a pediatric population. Pediatr Neurosurg 30:113-121, 1999

37. Loth F, Yardimci MA, Alperin N: Hydrodynamic modeling of cerebrospinal fluid motion within the spinal cavity. J Biomech Eng 123:71-79, 2001

38. Mampalam TJ, Andrews BT, Gelb D, et al: Presentation of type I Chiari malformation after head trauma. Neurosurgery 23: 760-762, 1988

39. Martinot A, Hue V, Leclerc F, et al: Sudden death revealing Chiari type 1 malformation in two children. Intensive Care Med 19:73-74, 1993

40. Menezes AH: Chiari I malformations and hydromyelia-complications. Pediatr Neurosurg 17:146-154, 1991-92

41. Menezes AH: Primary craniovertebral anomalies and the hindbrain herniation syndrome (Chiari I): data base analysis. Pediatr Neurosurg 23:260-269, 1995 


\section{Surgical treatment of Chiari I malformaion}

42. Milhorat TH, Chou MW, Trinidad EM, et al: Chiari I malformation redefined: clinical and radiographic findings for $364 \mathrm{symp}-$ tomatic patients. Neurosurgery 44:1005-1017, 1999

43. Munshi I, Frim D, Stine-Reyes R, et al: Effects of posterior fossa decompression with and without duraplasty on Chiari malformation-associated hydromyelia. Neurosurgery 46: 1384-1390, 2000

44. Nagib MG: An approach to symptomatic children (ages 4-14 years) with Chiari type I malformation. Pediatr Neurosurg 21: 31-35, 1994

45. Nakamura N, Iwasaki Y, Hida K, et al: Dural band pathology in syringomyelia with Chiari type I malformation. Neuropathology 20:38-43, 2000

46. Nishikawa M, Sakamoto H, Hakuba A, et al: Pathogenesis of Chiari malformation: a morphometric study of the posterior cranial fossa. J Neurosurg 86:40-47, 1997

47. Oldfield EH, Muraszko K, Shawker TH, et al: Pathophysiology of syringomyelia associated with Chiari I malformation of the cerebellar tonsils. Implications for diagnosis and treatment. J Neurosurg 80:3-15, 1994

48. Park JK, Gleason PL, Madsen JR, et al: Presentation and management of Chiari I malformation in children. Pediatr Neurosurg 26:190-196, 1997

49. Payner TD, Prenger E, Berger TS, et al: Acquired Chiari malformations: incidence, diagnosis, and management. Neurosurgery 34:429-434, 1994

50. Rekate HL, Nadkarni TD, Teaford PA, et al: Brainstem dysfunction in chiari malformation presenting as profound hypoglycemia: presentation of four cases, review of the literature, and conjecture as to mechanism. Neurosurgery 45:386-391, 1999
51. Santamarta D, Kusak ME, de Campos JM, et al: Increased cerebrospinal fluid flow through the foramen of Magendie after decompression for Chiari I malformation. J Neurol Neurosurg Psychiatry 66:799, 1999

52. Tokuno H, Hakuba A, Suzuki T, et al: Operative treatment of Chiari malformation with syringomyelia. Acta Neurochir Suppl 43:22-25, 1988

53. Wolpert SM, Bhadelia RA, Bogdan AR, et al: Chiari I malformations: assessment with phase-contrast velocity MR. AJNR 15:1299-1308, 1994

54. Wu YW, Chin CT, Chan KM, et al: Pediatric Chiari I malformations: do clinical and radiologic features correlate? Neurology 53:1271-1276, 1999

55. Yamazaki Y, Tachibana S, Takano M, et al: Clinical and neuroimaging features of Chiari type I malformations with and without associated syringomyelia. Neurol Med Chir 38:541-547, 1998

56. Yglesias A, Narbona J, Vanaclocha V, et al: Chiari type I malformation, glossopharyngeal neuralgia and central sleep apnoea in a child. Dev Med Child Neurol 38:1126-1130, 1996

57. Yundt KD, Park TS, Tantuwaya VS, et al: Posterior fossa decompression without duraplasty in infants and young children for treatment of Chiari malformation and achondroplasia. Pediatr Neurosurg 25:221-226, 1996

Manuscript received May 23, 2001.

Accepted in final form June 11, 2001.

Address reprint requests to: T. S. Park, M.D., Department of Pediatric Neurosurgery, St. Louis Children's Hospital, One Children's Place, Suite 4S20, St. Louis, Missouri 63110. 